\title{
Pulmonary artery coming from the aorta
}

INSERM

\section{Source}

INSERM. (1999). Orphanet: an online rare disease and orphan drug data base. Pulmonary artery coming from the aorta. ORPHA:99050

Pulmonary artery coming from the aorta (PACA) is a cardiac malformation characterized by anomalous origin of one branch of the pulmonary arteries from the ascending aorta and a normal orig in of the other pulmonary artery from the right ventricular outflow tract, and presenting with respiratory distress, congestive heart failure and failure to thrive within the first days/months of life. 